\title{
ESTIMATION OF THE DEPENDENCE PARAMETERS OF NUCLEAR STRUCTURAL MATERIALS HARDNESS ON THE CONTENT OF GAS IMPURITIES: AN INTERVAL APPROACH
}

\author{
T.V. Potanina ${ }^{I}$, O.V. Yefimov ${ }^{1}$, M.M. Pylypenko ${ }^{2}$ \\ ${ }^{1}$ National Technical University "Kharkiv Polytechnic Institute”, Kharkiv, Ukraine; \\ ${ }^{2}$ National Science Center "Kharkov Institute of Physics and Technology”, Kharkiv, Ukraine \\ E-mail:potaninatetiana@gmail.com;AVEfimov@kpi.kharkov.ua
}

The applications of the interval and standard probabilistic approaches for verifying the reliability of the results of an experiment studying the mechanical properties of nuclear materials are compared. The presence of "outliers" in a sample of hardness values for hafnium ingots is studied with for fixed oxygen mass content. The situation of measurement error limitation without reliable information about its distribution is considered. The correctness of the application of numerical methods of interval analysis for processing experimental data under conditions of uncertainty and noisy experimental data is shown. Determination of the dependence of the Brinell hardness of refined hafnium samples on the mass oxygen content was performed by a combination of methods: removal of anomalous measurements by interval analysis methods and approximation of data from truncated samples by the method Levenberg-Marquardt minimization.

\section{INTRODUCTION}

One of the priority tasks of the Ukrainian nuclear power industry is to extend the service life of one core load to 5-6 years and the entire reactor to 40-50 years. Therefore, regulatory bodies are needed, the performance and efficiency of which change insignificantly over a long time. Regulatory bodies using hafnium can operate throughout the entire service life of the reactor, that is, more than 30 years. According to domestic and foreign researchers, hafnium is an ideal material for control rods in pressurized water reactors; it can be successfully used as absorbing rods for control and safety systems of WWER-1000 reactors [1]. The hafnium rod among the rods in which boron carbide, chromium diboride, europium oxide is the absorbing material that has the maximum efficiency.

Another promising area of application of hafnium in nuclear technology is the manufacture of nuclear-safe and corrosion resistant equipment for the transportation and processing of spent nuclear fuel. Due to the large crossover of thermal neutron absorption, hafnium prevents the emergence of a chain fission reaction at high uranium and plutonium content in liquors. The high corrosion resistance of hafnium will increase the service life of such equipment. Abroad, this direction of hafnium application is noted as actively developing and has the prospect of becoming one of the leading ones as the volume of spent fuel processing increases.

Impurities found in hafnium significantly affect its properties. This can be said about penetration impurities, especially oxygen. With increased oxygen content in hafnium, it practically does not lend itself to mechanical processing. This fact, of course, severely limits the possibilities of its application in the form of products for nuclear power (sheets, rods, tubes, etc.).
It's known that when a metal is remelted at high temperatures in a vacuum, oxygen is removed from the metal into the gas phase in the form of volatile oxides that is distillation deoxidation is carried out. The analysis showed that at high oxygen concentrations, the distillation deoxidation of hafnium is carried out with significant overheating of the metal. Overheating leads to essential losses of hafnium. Thus, with at high oxygen content, the purification of hafnium by this method is ineffective.

The closeness of the properties of zirconium and hafnium (affinity for oxygen, oxidation, interaction with gases) suggests that the same refining methods from oxygen can be used for hafnium as for zirconium.

It is proposed to introduce to remove oxygen from hafnium in the electron-beam melting (EBM) process in the metal at the stage of reductive melting of the third component. This component used in deoxidation should have a greater affinity for oxygen. Its gaseous suboxide has higher volatility at the melting point of hafnium than the monoxide of the parent metal. Aluminum was chosen as the hafnium deoxidizer. The oxygen content in all hafnium samples obtained after EBM decreases almost three times: from $0.11 \ldots 0.12$ to $0.03 \ldots 0.04$ wt. $\%$. The aluminum content is $(2 \ldots 3) \cdot 10^{-3} \mathrm{wt} . \%$, whether or not aluminum additives were added. Hafnium, obtained using aluminum additives at the reduction stage, after refining by EBM, meets the specifications for hafnium of the GFE-1 grade, including for metallic impurities.

As the purity of hafnium increases, its hardness decreases from $\mathrm{HB}=1900 \ldots 2200 \mathrm{MPa}$ (oxygen content $0.10 \ldots 0.18 \mathrm{wt} . \%)$ for the output hafnium to values $\mathrm{HB}=1300 \ldots 1500 \mathrm{MPa}$ (oxygen content 0.03...0.05 wt.\%) after the EBM. A decrease in values is also characteristic of microhardness. 
The study of the samples presented at the permanent exhibition of high-purity substances (Institute of Chemistry of High-Purity Substances of the Russian Academy of Sciences) showed that gas-forming elements make a decisive contribution to the total content of impurities. Therefore, a further increase in the purity of these metals can be achieved by removing the main gas-forming impurities and impurities of analogous elements.

Each of the methods for producing pure hafnium has its advantages and disadvantages. The resulting hafnium ingots have differences in chemical composition within the technical requirements established for each method. The content of some impurities is limited only by maximum values. So, for example, the mass oxygen content for magnesium thermal hafnium ASTM B 737884 (USA, Europe) is $0.4 \%$ (grade R-1) and $0.08 \%$ (grade R-2), for iodide hafnium grade GFI-1 GOST 22517-77 (Russia), the actual gas content is within $0.02 \%$, the required oxygen concentration for calcium thermal hafnium grade KTG TU 95.2195-90 (Ukraine) is not more than $0.05 \%$ [2]. In other words, there are uncertainties in the data themselves, which assess the quality of the alloy ingot. This fact affects the accuracy of determining the dependences of hardness on the content of impurities and, in particular, oxygen.

This uncertainty is present in any process of research and evaluation of experimental data. It contains measurement errors, noise, round-off errors, incomplete information, methodological errors that give rise to uncertainty. It is impossible to overcome the conditions of all these uncertainties. An analysis of numerous scientific papers on the processing of experimental data shows that the interval model can be considered the best model in terms of the correctness of processing such data $[3,4]$. So, in $[5,6]$, for a more accurate determination of the dependence of the microhardness of $\mathrm{Zr} 1 \% \mathrm{Nb}$ alloy samples on the oxygen content in them in the presence of experimental data uncertainty, methods of interval analysis are used. Therefore, it is relevant to study the possibility of using interval analysis methods to study a sample of hardness values of hafnium alloy samples: to determine the dependence of the Brinell hardness of hafnium on gas impurities, if the sample is insignificant and there are "outliers" of observations. The authors propose to use some of the results obtained in [7].

\section{INITIAL DATA AND TASK SETTING}

A quantitative assessment of the effect of oxygen impurities on the mechanical properties of refined hafnium (hardness or microhardness of the metal) is usually performed by standard statistical methods of processing experimental results. For their application, it is necessary to fulfill significant assumptions about the properties of distortion of the data to be processed [8]:

- the sample to be measured is representative and of sufficient length;

- the total measurement error is probabilistic;
- the total error probability distribution is assumed to be a Gaussian Distribution;

- there are no chaotic components in the measurements;

- the errors of successive measurements are independent.

Unfortunately in practice, a sample of measurements is very short and the errors' probability characteristics are unknown.

In [9], Brinell hardness and chemical composition at the upper and lower ends of hafnium ingots smelted according to the EBM-VAM scheme (EBM, vacuumarc melting) are studied. The measurement results are presented in Fig. 1.
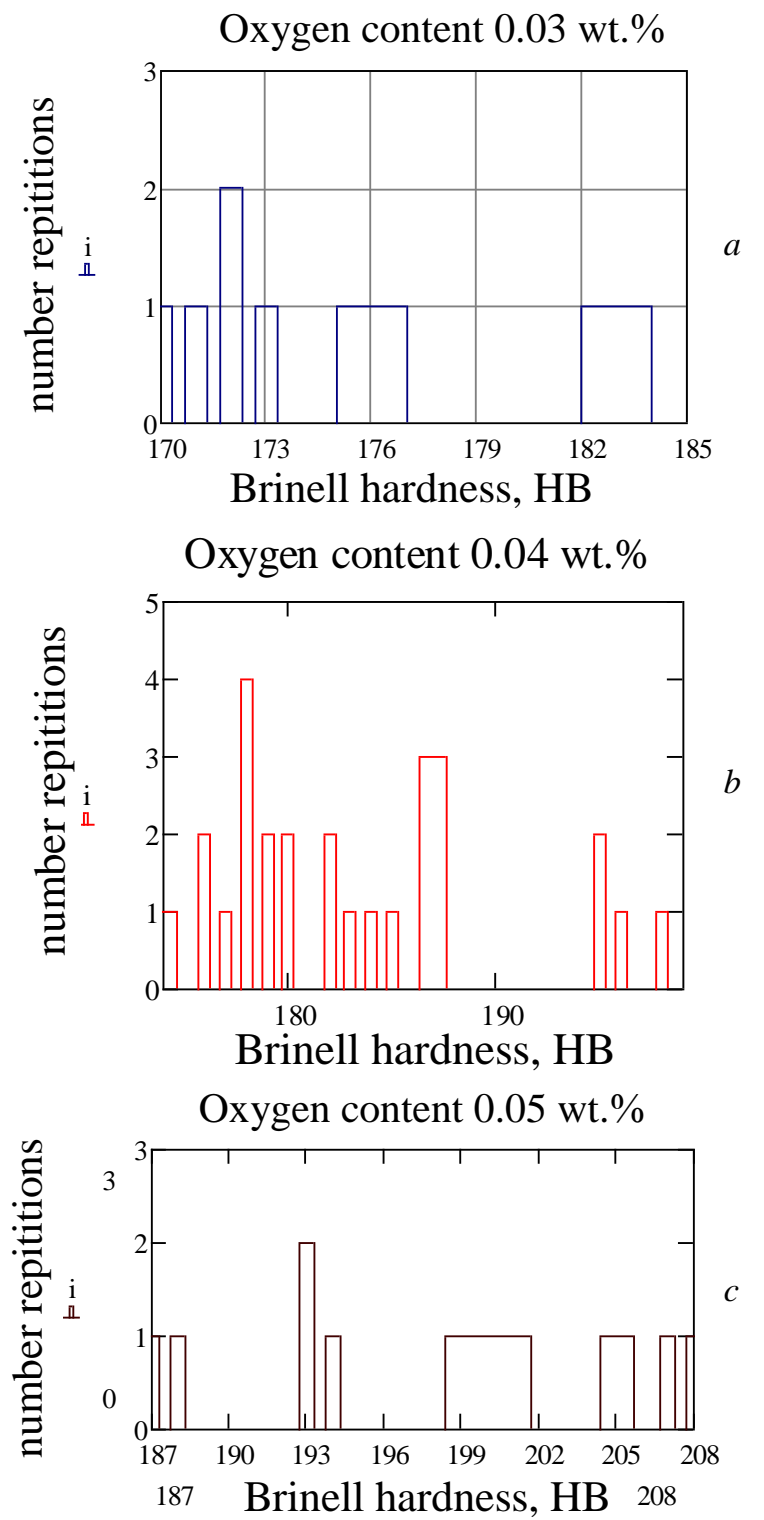

Fig. 1. Brinell hardness measurements result in different oxygen content: $a-0.03$;

$$
b-0.04 ; c-0.05 w t . \%
$$

It is necessary to process samples of noisy experimental data with a small number of values of the main argument (percentage weight content of oxygen) and multiple measurements in subsamples (hardness of hafnium ingots) for each of its values. Next, plot the 
dependence of the Brinell hardness of hafnium samples on the oxygen content in them.

The values of the argument are known for sure, and measurements in subsamples contain both usual instrumental measurement errors and chaotic distortions (corruptions) of an unknown magnitude. The probabilistic characteristics of both error components are unknown or not Normal; the limitation on the maximum value of the total errors is also uncertain.

\section{RESULTS AND THEIR DISCUSSION}

In the primary processing of experimental data, an important task is to exclude the results of observations with gross errors, which are outliers (anomalous measurements). We carry out this analysis for subsamples of experimental results presented in Fig. 1.

A subsample of Brinell's hardness values of samples with a weight fraction of oxygen of $0.03 \%$ contains $N=7$ observations:

$\left\{x_{i}, i=\overline{1,7}\right\}=\{172,170,183,176,172,173,171\} \mathrm{HB}$.

We cannot guarantee that observations are carried out with the same accuracy. Therefore, according to Standard [10], the standard instrumental error of Brinell's hardness measurement is taken to be $4 \%$. This value is allowed when the range of measured Brinell's hardness is $(200 \pm 50)$ HB. Thus, we restrict ourselves only to this measurement error and do not take into account other possible components of the total measurement error [11].

Sets of observational uncertainty $[8,12]$ :

$$
H_{i}=\left[\underline{h_{i}} ; \bar{h}_{i}\right]=\left[x_{i}-\Delta_{i} ; x_{i}+\Delta_{i}\right],
$$

where $\Delta_{i}-$ absolute error in i-observation.

So we get the intervals:

$H_{1}=[165.12 ; 178.88], H_{2}=[163.2 ; 176.8]$,

$H_{3}=[175.68 ; 190.32], H_{4}=[168.96 ; 183.04]$,

$H_{5}=H_{1}=[165.12 ; 178.88], H_{6}=[166.08 ; 179.92]$,

$H_{7}=[164.16 ; 177.84]$.

Using the boundaries of the uncertainty sets $H_{i}$, auxiliary extreme values are calculated (for all observations $i=\overline{1, N}$ ):

$$
h_{\min }=\max _{i} \underline{h_{i}}, h_{\max }=\min _{i} \bar{h}_{i} .
$$

Accordingly $\quad h_{\min }=175.68, h_{\max }=176.8, \quad$ i.e. $h_{\min } \leq h_{\max }$ and subsample is compatible, does not outliers.

The membership set $I=[175.68 ; 176.8]$.

Assessment of the central actual value

$$
\begin{aligned}
& x_{c}=\frac{h_{\min }+h_{\max }}{2}, \\
& x_{c}=176.24 .
\end{aligned}
$$

Maximum actual deviation

$$
\begin{gathered}
\Delta x=\frac{h_{\max }-h_{\min }}{2}, \\
\Delta x=0.56 .
\end{gathered}
$$

We now apply standard statistical methods for processing a subsample. Such an application is formal since the probabilistic characteristics of the observation error are unknown.

Sample mean

$$
\bar{x}=\frac{\sum_{i} x_{i}}{N}=173.857 .
$$

Standard deviation

$$
\sigma=\sqrt{\left[\sum_{i}\left(x_{i}-\bar{x}\right)^{2}\right] /[N-1]}=4.45 .
$$

The sample mean does not belong to the information set. The standard deviation is nearly eight times the maximum actual deviation: $\sigma \approx 8 \cdot \Delta x$.

The confidence interval

$$
\left[\bar{x}-t_{\mathrm{rr}} \cdot \frac{\sigma}{\sqrt{n}} ; \bar{x}+t_{\mathrm{rr}} \cdot \frac{\sigma}{\sqrt{n}}\right]=[168.863 ; 178.852],
$$

where $t_{\mathrm{kr}}-$ tabular value of Student's test.

Formal application of the " $3 \sigma$-rule" for outlier detection leads to the conclusion that the sample does not contain significant outliers: all values belong to the interval $[\bar{x}-3 \sigma ; \bar{x}+3 \sigma]=[160.505 ; 187.21]$. Rule " $2 \sigma$-rule" leads to the conclusion that experiment number three is a negligible outlier:

$$
183 \notin[\bar{x}-2 \sigma ; \bar{x}+2 \sigma]=[164.956 ; 182.759] \text {. }
$$

Another way to identify outliers is to use the sample median. The median is the simple and most robust estimate of the shift parameter for a sample with a small amount of anomalous data. For such data, the sample mean may give an unsatisfactory result. Outliers can be considered points that are outside the interval

$$
[\operatorname{med}-3 \cdot \sigma(\text { med }) ; \text { med }+3 \cdot \sigma(\text { med })],
$$

where med - the median; $\sigma($ med $)$ - the mean square error for the median. Applying the " $3 \sigma$-rule" for the sample median and the mean square error for the median does not detect outliers in the sample. Here this interval includes all sample points:

$$
\text { [157.354;186.646], med }=172 \text {. }
$$

Among the various criteria that reliably determine outliers in small (up to 20 values) samples, the Lvovsky's criterion [13] has proven itself well. A suspicious observation $\tilde{x}$ is considered an outlier and is excluded from the sample if the table value of the Lvovsky's criterion $K r L$ is true:

$$
K r L<\frac{|\tilde{x}-\bar{x}|}{\sqrt{D} \cdot \sqrt{n-1 / n}},
$$

where $D$ - variance.

The L'vovskiy's criterion is parametric and assumes that the sample under study has a Normal distribution.

For a hardness value of 183 , the calculated value of the Lvovsky's criterion is 2.396, and the tabular value for a sample of seven values is $K r L=2.09$. Conclusion: this value is an outlier. 
Thus, classical statistical methods for determining outliers give contradictory results. The reasons have been given above.

Let us apply the same scheme for examining the sample for the presence of the outliers for the following two experiments: the oxygen content is 0.04 and 0.05 wt.\%. Let's carry out a comparative analysis of the application of statistical methods and methods of interval analysis.

Consider the subsample of hardness values with a weight percentage of oxygen equal to $0.04 \%$. This sample consists of 24 observations (see Fig. 1,b):

$\left\{x_{i}, i=\overline{1,24}\right\}=\{178,176,187,184,180,178$,

$182,185,179,187,182,174,179,177,180$,

178, 178, 183, 176, 198, 195, 187, 196, 195\} HB.

We find the boundaries of the uncertainty sets $H_{i}$ and extreme values $h_{\min }, h_{\max }$ by the formulas (1)-(2):

$$
h_{\min }=190.08, h_{\max }=180.96 \text {. }
$$

Since $h_{\min }>h_{\max }$, the subsample incompatible. Additional sample analysis is needed.

The procedure for finding single outliers:

1. The set of pairwise intersections of all sets $H_{i}$ and $H_{j}$ is calculated

$$
P_{i j}=H_{i} \cap H_{j}, i=\overline{1, N-1}, j=\overline{i+1, N},
$$

the boundaries of the set $P_{i j}$

$$
\underline{p_{i j}}=\max \left\{\underline{h_{i}}, \underline{h_{j}}\right\}, \overline{p_{i j}}=\min \left\{\overline{h_{i}}, \overline{h_{j}}\right\} .
$$

2. If $\underline{p_{i j}}>\overline{p_{i j}}$, then $P_{i j}=\varnothing$ and compatibility attribute value $S_{i j}=0$.

If $p_{i j} \leq \overline{p_{i j}}$, then $P_{i j} \neq \varnothing$ and compatibility attribute value $S_{i j}=1$.

3. Building a compatibility table

$$
\left\{S_{i j}, S_{i j}=S_{j i},\right\}, i=\overline{1, N-1}, j=\overline{i+1, N} \text {. }
$$

4. Observation number $i$ is a single outlier and is deleted if its row in the compatibility table consists of zeros. Single outliers are deleted and the sample is truncated.

Next, using the compatibility table, we determine the compatible subsample of the maximum length.

The row $m$ (or rows $m_{1}, \ldots, m_{l}$ ) with the maximum number of units is selected: columns $j_{1}, \ldots, j_{k}$. The first of the columns $j_{1}$ with a single value of the compatibility attribute is taken. All column elements are viewed from top to bottom. Elements with $S_{i j}=0$ are deleted from the sequence $j_{1}, \ldots, j_{k}$. The operation is repeated for all columns. We get a set of observation numbers that make up a compatible subsample of the maximum length.

The compatibility matrix for this subsample is presented in Table 1.
Trivial cells located on the main diagonal of the table do not participate in the analysis of sample compatibility.

Table 1

Attributes of pairwise compatibility of uncertainty sets

\begin{tabular}{|c|c|c|c|c|c|c|c|c|}
\hline $\mathbf{i} / \mathbf{j}$ & $\mathbf{1}$ & $\mathbf{2}$ & $\ldots$ & $\mathbf{2 0}$ & $\mathbf{2 1}$ & $\mathbf{2 2}$ & $\mathbf{2 3}$ & $\mathbf{2 4}$ \\
\hline $\mathbf{1}$ & & 1 & $\ldots$ & 0 & 0 & 1 & 0 & 0 \\
\hline $\mathbf{2}$ & 1 & & $\ldots$ & 0 & 0 & 1 & 0 & 0 \\
\hline$\ldots$ & $\ldots$ & $\ldots$ & & $\ldots$ & $\ldots$ & $\ldots$ & $\ldots$ & $\ldots$ \\
\hline $\mathbf{2 0}$ & 0 & 0 & $\ldots$ & & 1 & 1 & 1 & 1 \\
\hline $\mathbf{2 1}$ & 0 & 0 & $\ldots$ & 1 & & 1 & 1 & 1 \\
\hline $\mathbf{2 2}$ & 1 & 1 & $\ldots$ & 1 & 1 & & 1 & 1 \\
\hline $\mathbf{2 3}$ & 0 & 0 & $\ldots$ & 1 & 1 & 1 & & 1 \\
\hline $\mathbf{2 4}$ & 0 & 0 & $\ldots$ & 1 & 1 & 1 & 1 & \\
\hline
\end{tabular}

There are no null rows in Table 1 . Therefore, the sample does not contain single outliers.

Using the presented algorithm, we determine that observations No. 20, 21, 23, 24 are outliers. We are building a truncated sample. For this sample:

$h_{\min }=179.52, h_{\max }=180.96$, i.e. $h_{\min } \leq h_{\max }$ and sample is compatible.

The membership set: $I=[179.52,180.96]$. Assessment of the central actual value: $x_{c}=180.24$. Maximum actual deviation: $\Delta x=0.72$.

Probabilistic characteristics: the sample mean value $-\bar{x}=183.083$; the standard deviation $-\sigma=6.921$; the median - med $=181$; the mean square error for the median $-\sigma($ med $)=7.241$.

According to the " $2 \sigma$-rule", the outlier is $198 \mathrm{HB}$; according to the " $3 \sigma$-rule", there are no outliers. According to the " $3 \sigma$-rule" for the median, there are also no outliers.

We calculate the Lvovsky's criterion for "suspicious" values 195, 196, 198 HB (9): the tabular value $\operatorname{KrL}(24)=2.7$, and

$$
\begin{aligned}
& 2.7>\frac{|195-183.083|}{6.776 \cdot \sqrt{23 / 24}}=1.797, \\
& 2.7>\frac{|196-183.083|}{6.776 \cdot \sqrt{23 / 24}}=1.947, \\
& 2.7>\frac{|198-183.083|}{6.776 \cdot \sqrt{23 / 24}}=2.249 .
\end{aligned}
$$

Therefore, these points are not outliers.

Consider the last subsample of hardness values with a weight percentage of oxygen equal to $0.05 \%$. This sample consists of nine observations (see Fig. 1,c):

This sample consists of 24 observations (see Fig. $1, b)$ :

$$
\left\{x_{i}, i=\overline{1,9}\right\}=\{194,187,208,188,207,200,
$$

193, 193, 205\} HB. 
The research scheme already familiar to us leads to the following results. The uncertainty sets constructed by the method of interval estimates for the values of this subsample allow us to conclude that the sample is incompatible since

$$
h_{\min }=199.68, h_{\max }=194.48 \text {, i. e. } h_{\min }>h_{\max } .
$$

The outlier identification procedure made it possible to construct a compatibility matrix (Table 2 ).

Table 2

Attributes of pairwise compatibility of uncertainty sets

\begin{tabular}{|l|l|l|l|l|l|l|l|l|l|}
\hline $\mathbf{i} / \mathbf{j}$ & $\mathbf{1}$ & $\mathbf{2}$ & $\mathbf{3}$ & $\mathbf{4}$ & $\mathbf{5}$ & $\mathbf{6}$ & $\mathbf{7}$ & $\mathbf{8}$ & $\mathbf{9}$ \\
\hline $\mathbf{1}$ & & 1 & 1 & 1 & 1 & 1 & 1 & 1 & 1 \\
\hline $\mathbf{2}$ & 1 & & 0 & 1 & 0 & 1 & 1 & 1 & 0 \\
\hline $\mathbf{3}$ & 1 & 0 & & 0 & 1 & 1 & 1 & 1 & 1 \\
\hline $\mathbf{4}$ & 1 & 1 & 0 & & 0 & 1 & 1 & 1 & 0 \\
\hline $\mathbf{5}$ & 1 & 0 & 1 & 0 & & 1 & 1 & 1 & 1 \\
\hline $\mathbf{6}$ & 1 & 1 & 1 & 1 & 1 & & 1 & 1 & 1 \\
\hline $\mathbf{7}$ & 1 & 1 & 1 & 1 & 1 & 1 & & 1 & 1 \\
\hline $\mathbf{8}$ & 1 & 1 & 1 & 1 & 1 & 1 & 1 & & 1 \\
\hline $\mathbf{9}$ & 1 & 0 & 1 & 0 & 1 & 1 & 1 & 1 & \\
\hline
\end{tabular}

The anomalous measurements are Brinell hardness values of 205, 207, $208 \mathrm{HB}$ (measurements No. 3, 5 9 ). The truncated sample contains five values (the value $193 \mathrm{HB}$ is repeated twice). For this sample:

$h_{\min }=192, h_{\max }=194.48$, i.e. $h_{\text {min }} \leq h_{\max } \quad$ and sample is compatible.

The membership set: $I=[192,194.48]$. Assessment of the central actual value: $x_{c}=193.24$. Maximum actual deviation: $\Delta x=1.24$.

Methods for identifying outliers, based on a probabilistic approach and the assumption that the sample obeys the Normal Distribution, did not reveal a single outlier. Namely, the sample mean value $\bar{x}=197.222$; the standard deviation $-\sigma=8.028$; the median - med $=194$; the mean square error for the median $-\sigma($ med $)=8.725$; interval

$$
[\bar{x}-2 \sigma ; \bar{x}+2 \sigma]=[181.167 ; 213.278]
$$

includes all values from the subsample; interval

$$
\begin{aligned}
& {[\text { med }-3 \cdot \sigma(\text { med }) ; \text { med }+3 \cdot \sigma(\text { med })]=} \\
& =[167.825 ; 220.175]
\end{aligned}
$$

includes all values from the subsample; Lvovsky's criterion for suspicious points 205, 207, $208 \mathrm{HB}$ does not identify them as outliers.
Let us compare the results of processing all three subsamples for the presence of the outliers, carried out by methods of interval analysis and probabilistic methods. According to interval estimation, truncated subsamples are characterized by uncertainty intervals $H^{0.03 \%}=[175.68 ; 176.8], H^{0.04 \%}=[179.52 ; 180.96]$, $H^{0.05 \%}=[192.0 ; 194.48]$ (superscripts indicate the oxygen percentage for a given subsample); with central actual values $\mathbf{x}_{\mathrm{c}}=(176.24,180.24,193.24)$. Classical statistical methods, after removing outliers from the first and second subsamples, determined the mean values in the samples $\overline{\mathbf{x}}=(172.333,182.435,197.222)$. It is obvious that all these points are outside the uncertainty intervals. Let's calculate the average sample values for subsamples truncated by interval analysis methods. We get the values $\overline{\mathbf{x}}_{\text {kor }}=(173.857,181.0,192.0)$. In Fig. 2, these values are called "corrected mean values". The dotted lines show the boundaries of the tube built on the uncertainty intervals. Two values from the sample means, calculated for subsamples truncated by the interval method, are on the border of the uncertainty tube. Thus, the combination of methods improves the accuracy of the estimate.

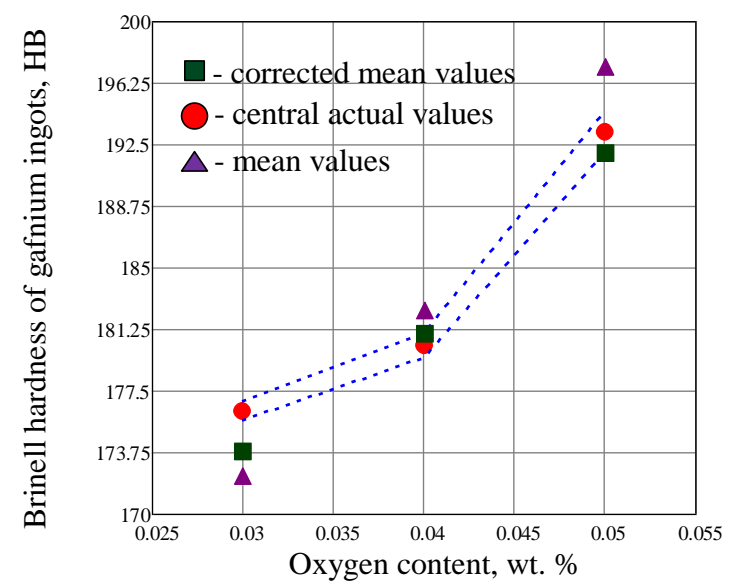

Fig. 2. Brinell hardness values: sample mean after removal of outliers by probabilistic and interval analysis methods, central actual values

The examples considered show that if the sample of experimental data is small with gross errors of observation, the interval analysis method gives better accuracy indicators than the standard statistical method. As well as calculated estimates of the actual value of hardness and uncertainty indicators of experimental data, it is possible to maintain reliable observations in a situation where, according to standard statistical methods, the sample must be truncated.

Determination of the dependence of the hardness of hafnium samples on the weight oxygen content is performed by a combined method. 


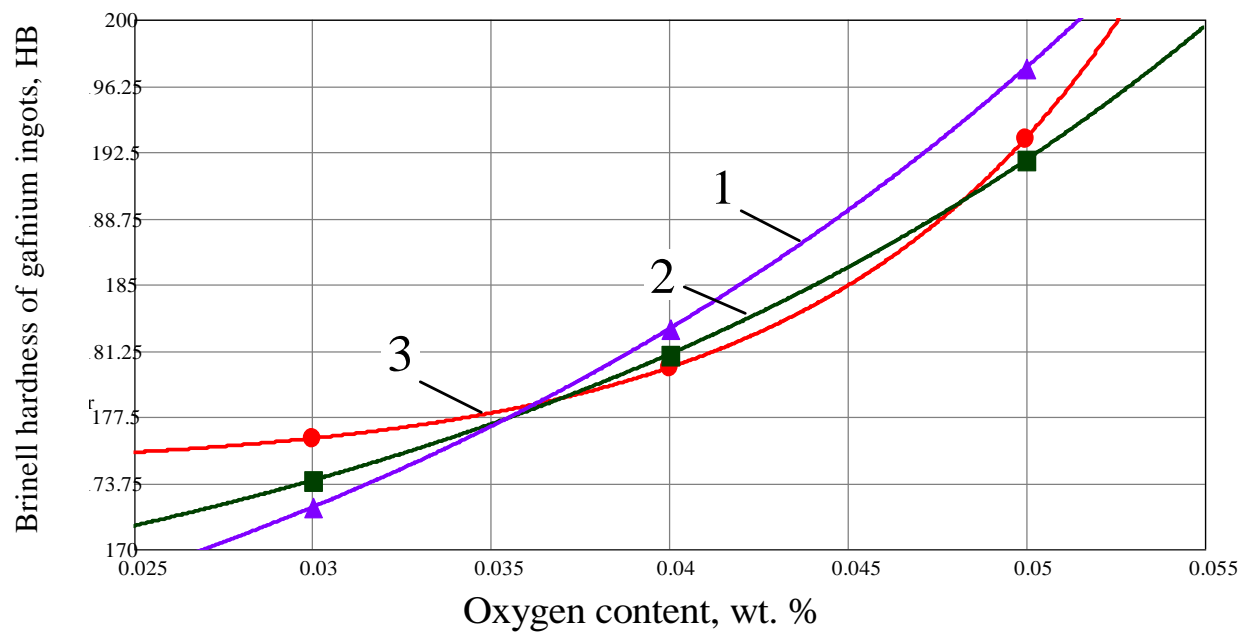

Fig. 3. The dependence of the Brinell hardness of hafnium samples on the weight oxygen content:

1 -approximation by mean values of the sample; 2 - approximation by corrected mean values of the sample; 3 - approximation by central actual values

As an approximating curve, we considered a dependence of the form $f(x)=a \cdot e^{b x}+c$. Using standard statistical approaches to experimental data processing and based on the fact that the dependence is not a linear function, the parameters of the ratio $f(x)=a \cdot e^{b x}+c$ are determined by the method of Levenberg-Marquardt minimization [14].

Curve 1 in Fig. 3 shows the line

$$
f_{1}(x)=6.945 \cdot e^{38.101 x}+150.551 \text {, }
$$

when the hardness values were statistical mean values.

Curve 2 in Fig. 3 shows the line

$$
f_{2}(x)=3.622 \cdot e^{43.176 x}+160.628,
$$

when the hardness values were corrected mean values of the sample.

Curve 3 in Fig. 3 shows the line

$$
f_{3}(x)=0.052 \cdot e^{117.865 x}+174.462,
$$

when the hardness values were central actual values.

Curve 1 does not pass through all the uncertainty intervals and, thus, gives a rougher estimate of the dependence of the hardness of hafnium samples on the oxygen content. Curve 2 is a more accurate estimate and is close to curve 3 . Therefore, the construction of an approximating line at the nodes determined for samples truncated by interval analysis methods is a more efficient approach for processing observational data.

\section{CONCLUSIONS}

The use of interval analysis methods provides an alternative flexible tool for obtaining more accurate and complete analysis of experimental data in the presence of incomplete information, noise, outliers measurements, which is typical when conducting studies of the hardness of refined hafnium ingots. Studies carried out to solve the problem of restoring the dependence of the mechanical properties of metal on oxygen impurities show that according to the data processed by interval analysis methods, the further approximation problem is effectively solved by basic regression analysis methods.

\section{REFERENCES}

1. M.M. Pylypenko. Hafnium: obtaining, refining, properties. Kharkiv: FOP Panov A.M., 2020, 236 p. (in Ukrainian).

2. G.A. Kolobov, V.V. Pavlov, A.V. Karpenko, A.G. Kolobova. Refining refractory rare metals of group IV of the periodic table // Novi materialy i tekhnolohiyi $v$ metalurhiyi ta mashynobuduvanni. 2015, N 1, p. 89-95 (in Ukrainian).

3. R.E. Moore, R.B. Kearfott, M.J. Cloud. Introduction to interval analysis. Society for Industrial and Applied Mathematics, Philadelphia, 2009, 223 p.

4. S.P. Shary. The finite-dimensional interval analysis. Novosibirsk, XYZ Publ., 2016, 606 p. (in Russian).

5. A.V. Yefimov, M.M. Pylypenko, T.V. Potanina, et al. Processing of experimental data of the process of refining nuclear material $\mathrm{Zr} 1 \% \mathrm{Nb}$ by electron-beam melting by means of interval analysis methods // Problems of Atomic Science and Technology. Series "Physics of Radiation Effect and Radiation Materials Science". 2019, N 5, p. 118-123.

6. O. Yefimov, M. Pylypenko, T. Potanina, et al. Materials and decision support systems in the nuclear power industry. LAPLAMBERT Academic Publishing, 2020, 135 p.

7. T.V. Potanina, O.V. Yefimov. Application of interval analysis for improving the reliability of the assessment of hardness values spread of nuclear structural materials // Problems of Atomic Science and Technology. Series "Physics of Radiation Effect and Radiation Materials Science". 2020, N 1, p. 206-210.

8. S.I. Kumkov, Yu.V. Mikushina. Interval Approach to Identification of Catalytic Process Parameters // Realible Computing. 2013, N 19(2), p. 197-214.

9. N.K. Filatova. Scientific substantiation of the optimal parameters of industrial technology for the 
production of hafnium ingots for the nuclear industry: Doctoral thesis. M., 2016, 157 p.

10. National standard of Ukraine. Metallic materials - Brinell hardness test - Part 2: Verification and calibration of testing machines (ISO 6506-2:2005, IDT). Kyiv: State consumer standard of Ukraine, 2010, 11 p.

11. Guidelines of the state enterprise «National Atomic Energy Generating Company "Energoatom"»: Methods for determining the mechanical properties of metal by hardness tests. Kyiv, 2016, 33 p.

12. S.I. Kumkov. Interval approach to processing noisy experimental data with multiple measurements under conditions of uncertainty // International Conference "Contemporary Problems of Applied
Mathematics and Mechanics: Theory, Experiment, and Practice", 2011.

13. Ye.N. L'vovskiy. Statistical methods for constructing empirical formulas: Textbook for technical colleges. M.: "Vysshaya shkola", 1988, 293 p. (in Russian).

14. K. Madsen, N.B. Nielsen, O. Tingleff. Methods for nonlinear least squares problems. Technical Report. Informatics and Mathematical Modeling, Technical University of Denmark, 2004, 58 p.

\section{ОЦЕНКА ПАРАМЕТРОВ ЗАВИСИМОСТИ ТВЕРДОСТИ ЯДЕРНЫХ КОНСТРУКЦИОННЫХ МАТЕРИАЛОВ ОТ СОДЕРЖАНИЯ ПРИМЕСЕЙ ГАЗОВ МЕТОДАМИ ИНТЕРВАЛЬНОГО АНАЛИЗА}

Article received 30.08 .2021

\section{Т.В. Потанина, А.В. Ефимов, Н.Н. Пилипенко}

Проведен сравнительный анализ применения интервального и стандартного вероятностного подходов для проверки достоверности результатов эксперимента по изучению механических свойств ядерных материалов. Исследуется выборка значений твердости образцов слитков гафния при одинаковом массовом содержании кислорода на наличие выбросов. Рассматривается ситуация ограниченности погрешности измерений без достоверной информации о ее распределении. Показана корректность применения численных методов интервального анализа для обработки экспериментальных данных в условиях неопределенности и зашумленности. Определение зависимости твердости по Бринеллю рафинированных образцов гафния от массового содержания кислорода выполнено комбинацией методов: удаление аномальных измерений методами интервального анализа с последующей аппроксимацией данных из усеченных выборок методом минимизации Левенберга-Марквардта.

\section{ОЦІНКА ПАРАМЕТРІВ ЗАЛЕЖНОСТІ ТВЕРДОСТІ ЯДЕРНИХ КОНСТРУКЦЙНИХ МАТЕРІАЛІВ ВІД ВМІСТУ ДОМІШОК ГАЗІВ МЕТОДАМИ ІНТЕРВАЛЬНОГО АНАЛІЗУ}

\section{Т.В. Потаніна, О.В. Сфімов, М.М. Пилипенко}

Проведено порівняльний аналіз застосування інтервального і стандартного ймовірнісного підходів для перевірки достовірності результатів експерименту з вивчення механічних властивостей ядерних матеріалів. Досліджується вибірка значень твердості зразків злитків гафнію при однаковому масовому вмісті кисню на наявність викідів. Розглядається ситуація обмеженості похибки вимірювань без достовірної інформації про iii розподіл. Показана коректність застосування чисельних методів інтервального аналізу для обробки експериментальних даних в умовах невизначеності і наявності «шуму» в них. Визначення залежності твердості за Брінеллем рафінованих зразків гафнію від масового вмісту кисню здійснено за допомогою комбінації методів: видалення аномальних значень методами інтервального аналізу 3 наступною апроксимацією даних з усічених вибірок методом мінімізації Левенберга-Марквардта. 